\title{
Antecedentes y temáticas de la investigación universitaria venezolana sobre Latinoamérica y el Caribe
}

Background and topics of Venezuelan university research on Latin America and the Caribbean

\author{
Raúl García Palma ${ }^{1}$
}

\begin{abstract}
Resumen
Siguiendo la caracterización de Foucault (1984), sobre formaciones discursivas como espacio histórico, con un discurso donde diferentes enunciados surgen en contraste y competencia, se expone lo encontrado en la siguiente investigación, cuando su mayor objetivo es presentar las formaciones discursivas del discurso escrito sobre América Latina y el Caribe. En los textos propuestos como objetos de ese discurso, les fue aplicado el criterio de la presencia de argumentos, por medio de las tesis contenidas en los mismos. Se interpretaron cinco tesis, en textos considerados importantes para autores de diversas universidades del país y que han sido verificados por la lectura previa, siguiendo el modelo de esquema argumentativo (Cordero, 2000). En ellos se caracterizó sus búsquedas y también, el sentido en los cambios que puedan presentar dentro de sus enunciados metafóricos, interpretándolos con el Análisis del Discurso (Hall, 2010). Además, se afrontó el proceso para responder al cómo surgieron modelos de representación de lo real dentro de los textos, siguiendo la metodología de situación de Zwaan (Ibáñez, 2007). En el diálogo autoral de la formaciones discursivas del discurso escrito sobre América Latina y el Caribeabordado, se concluyó que los autores universitarios venezolanos, enuncian un sujeto donde pervive la relación de naciones con historias parecidas, que las convierte también en culturas de una región, en ella surge la necesidad de colocar la siguiente afirmación

\footnotetext{
${ }^{1}$ Doctor en Ciencias de la Educación. Magister en Literatura Latinoamericana y en Ciencias de la Educación Universitaria. Docente y escritor. Sociólogo. Profesor de pensamiento latinoamericano y metodología de la investigación en la Universidad Nacional Experimental de los Llanos Occidentales Ezequiel Zamora (Unellez). Publicaciones de libros de ensayo Historia y ficción en Armas Alfonzo (Barinas, Fundación Cultural, 2000), Armas Alfonzo. Ensayos sobre su obra (Caracas, Conac, 2000), El ensayo lezámico (El Perro y la rana-2007) y Las crónicas de Indias como referente en la narrativa de José León Tapia (Unellez-2010). Barinas, Venezuela. Correo electrónico: garciapalma.rgp@ gmail.com
} 


\section{Antecedentes y temáticas de la investigación universitaria venezolana sobre}

Latinoamérica y el Caribe

como principio de integración y como política: "el otro sabe que existes, porque tienes prácticas de creación" modalidad de diálogo que para Roig (2008), autor base en estos investigadores, es parte del modelaje para llegar a representarla. Con esta aseveración, los diferentes enunciados del discurso escrito bajo reflexión, se construyen en confrontación, aspecto que determina un escenario asimétrico y coloca a la región y a los interpretantes que buscan conceptualizarla, en la interrogación permanente del horizonte de su práctica existencial y en la vigilancia del hacer sobre su identidad.

Palabras Claves: Pensamiento Latinoamericano, Cultura latinoamericana y Caribeña, Investigación Universitaria, Formación Discursiva.

RECIBIDO: Octubre 2017

ACEPTADO: Noviembre 2017

Abstract
Following the characterization of Foucault (1984), on discursive formations as historical space, with a speech where different terms of reference arise in contrast and competition, it is exposed found in the following investigation, when his major aim is to present the discursive formations of the speech written on Latin America and the Carib. In the texts proposed as objects of this speech, there was applied to them the criterion of the presence of arguments, by means of the theses contained in the same ones. Five theses were interpreted, in considered important texts for authors of diverse universities of the country and that have been checked by the previous reading, being still the model of argumentative scheme (Lamb, 2000). In them his searches were characterized and also, the sense in the changes that they could present inside his metaphorical terms of reference, interpreting them with the Analysis of the Speech (Hall, 2010). In addition, the process was confronted to answer to how there arose models of representation of the royal thing inside the texts, following the methodology of Zwaan's situation (Ibáñez, 2007. In the dialog autoral of discursive formations of the speech written on Latin America and the approached Carib, one concluded that the university Venezuelan authors, they enunciate a subject where pervive the relation of nations with similar histories, which it turns them also into cultures of a region, in her arises the need to place the following affirmation as beginning of integration and as politics: " other one knows that you exist, because you have practices of creation " modality of dialog that for Roig (2008), author bases on these investigators, it is a part of the modeling to manage to represent her. With this affirmation, the different terms of reference of the speech written under reflection, they are constructed in confrontation, aspect that determines an asymmetric scene and places the region and 


\section{Raúl García Palma}

Telos Vol. 20, No. 1 (2018). 159-198

the interpretantes that seek to conceptualize it, in the permanent interrogation of the horizon of his existential practice and in the vigilance of to do on his identity.

Keywords: Latin-American Thought, Latin-American and Caribbean Culture, University Investigation, Discursive Formation.

\section{Introducción}

El sujeto del texto académico del discurso escrito sobre América Latina y el Caribe, se ha constituido dentro de un proceso histórico, allí su lugar de enunciación se ha desplazado a lo largo de una relación de significación. Su posición en esta relación, se buscará caracterizar, en cuanto a sus temáticas y antecedentes, también se habrá de interpretar cómo su transcurso escritural refleja posiciones ideológicas que permiten la verificación de la memoria regional.

Los textos de investigación universitaria venezolana, permiten indagar la necesidad de presentar la simbología de un nosotros, allí se manifiesta la axiología de ese lugar. Esta valorización del nosotros como necesidad psico-social de las culturas que conforman la región, se presenta en textos escritos denominados discurso académico.

De todas maneras, podemos decir que existe cierto consenso en considerar que eldiscurso académico es el que permite la 'comunicación' de contenidos, en contexto de estudio. Con esta designación se remite a los textos (orales y escritos) que se producen y circulan en ámbitos de estudios superiores y, en este sentido, se lo relaciona, indefectiblemente, con conocimientos disciplinares llamados científicos. (Hall, 2010, p. 197).

El espacio donde se despliega este discurso, busca la legitimidad de ser llamado científico al tratar como contenido a lo latinoamericano y caribeño. La legitimación se conjuga por medio de códigos socioculturales, éstos son variados, con cambios en su carga de significancia. Los que perduran en la historia dentro de una cultura, son propuestos por Foucault (1984) como enunciados, aquellos acontecimientos singulares que constituyen el archivo de un discurso, estos enunciados aparecen, desaparecen o se ordenan en formaciones discursivas, que se 
Antecedentes y temáticas de la investigación universitaria venezolana sobre Latinoamérica y el Caribe

van diferenciando. En esta investigación, se ha ordenado una red de formaciones discursivas desde una caracterización que la motiva y que se ha denominado: Dimensión de conocimientos y saberes multiregionales.

Estos conocimientos y saberes se exhiben por medio de la historia, antropología, sociología y literatura. Desde estas disciplinas se presentan los siguientes textos, codificados con la primera letra del apellido de sus autores. Tesis D: Agentes de su libertad (Dávila, 2010); Tesis A: Independencia y emancipación (Acosta, 2010); Tesis Q: Sueños y palabras de América Latina (Quintero, 2008); Tesis G: Caribeñidad (García, 2007) y Tesis B: Políticas de la teoría. Ensayos sobre la subalternidad y hegemonía (Beverly, 2011). Los autores son docentes universitarios o han tenido relación con centros de investigación del país, además sus trabajos han sido motivo de premios o son pioneros en sus espacios de discusión, en cuanto su compromiso con los códigos que tratan de definir e intermediar en este espacio cultural diverso. Desde esta última acción, se ha escogido al libro de la profesora Dávila, por intentar reconocer aspectos nuevos en la memoria del Caribe; como productor de imaginarios sociales al texto del Profesor Acosta; la revisión amplia del imaginario latinoamericano, por medio de la Profesora Quintero y por último dos libros en conjunto, que conformarán un mismo punto o apartado, donde se intentó responder a las siguientes preguntas: el autor o los autores ¿explican la lectura semiótica de las memorias locales de Latinoamérica y el Caribe buscando consenso para denominar su análisis como científico? y ¿Se explica la diversidad cultural en la historia de Latinoamérica y el Caribe como la búsqueda de un planteamiento político diferente a otro que deslegitima esta postura? Las mismas se rectificarán en la presencia escritural de la caribeñidad del Profesor García, en su búsqueda de la identidad y la memoria colectiva, por otra parte en la legitimación de nuevos códigos en la región por medio del libro del investigador Beverley.

En cada uno de los textos anteriores, se le aplicará el criterio de la presencia de argumentos, por medio de las tesis que puedan contener. Se ha estimado interpretar 


\section{Raúl García Palma}

Telos Vol. 20, No. 1 (2018). 159-198

cinco tesis en cada uno y que han sido verificados por la lectura previa, siguiendo el modelo de esquema argumentativo (Cordero, 2000); se verificará en los libros, sus búsquedas y también, el sentido en los cambios que puedan presentar dentro de sus enunciados metafóricos interpretándolos con el Análisis del Discurso (Hall, 2010). También se abordó, el proceso que podría ser clave para conocer el cómo surgen modelos de representación de lo real dentro del texto, en este caso dentro de la dimensión de conocimientos y saberes multiregionales y en los niveles de diálogos del discurso escrito sobre América Latina, con más detalle en el nivel de Ciencias Integradas, siguiendo al modelo de situación de Zwaan (Ibáñez, 2007), al que le fue incorporado cambios por parte del autor de la investigación.

\section{A los textos Caribeñidad y Políticas de la teoría. Ensayos sobre la} subalternidad y hegemonía, de los profesores García y Beverly, se le ha hecho una interpretación sobre tres tesis en cada uno, característica que pudo relacionar la importancia de la memoria para re-configurar la historia, además la relación de la visión de los embates del colonialismo en el Caribe y su aprovechamiento como narración por la subalternidad. A lo largo de las interpretaciones que a continuación se presentan hay una manera de pensar, un asomo o actitud de los autores sobre la modernidad como la alteridad donde la región se problematiza, quizás por el momento que se señala, explicado por el autor Mazorco, como cambio estructural, donde la modernidad da paso a otras narrativas.

Desde las dos últimas décadas del siglo XX, la crisis de la modernidad ha generado como respuesta una serie de proyectos que pretenden trascenderla. Todos la presentan como una crisis esencialmente epistémica. Uno de ellos, el proyecto posmodernista... Los otros proyectos, como los estudios subalternos, los postcoloniales y los postoccidentales, se formulan desde la subalternidad del tercer mundo y cuestionan al paradigma de la modernidad, entendido como el proyecto de occidentalización del planeta; pretenden instaurar un quiebre epistemológico que dé lugar a todos los conocimientos que fueron subalternizados por la colonialidad del poder y del saber (2010, p. 222). 
Antecedentes y temáticas de la investigación universitaria venezolana sobre Latinoamérica y el Caribe

Se presentan cinco lecturas, con diferentes tesis para ser comprendidas como búsquedas de enunciados que hagan posible, la garantía y continuidad de la identidad latinoamericana y caribeña por medio de su escritura, en ella se exponen los textos y contextos del discurso de esta región en modelos y proyectos aún no muy claros en el debate.

\section{Preponderancia de compromiso por los códigos socioculturales}

La identidad, un código sociocultural, que ya se puede considerar un enunciado, puede ser catalogado como transversal en el denominado discurso escrito sobre América Latina y el Caribe, genera en los autores que lo desarrollan hondos compromisos que los convierten en interpretantes (García Palma, 2013). Es decir, su acción de focalizarlo, los obliga a debatirse desde un diálogo ya establecido con el mismo, que tiene diversos puntos de vistas. Desde aquellos que defienden a la identidad latinoamericana como sólo indígena; aquellos que colocan el peso en la tradición hispánica; los occidentalistas que refieren la pertenencia de América Latina, esta pertenecía sería de aproximación en cuanto a que la modernización depende de lo mucho o poco que se parezcan estos pueblos a Europa y Estados Unidos; la mestiza que defiende una cultura de encuentro con nuevas formas, con grados como la defendida por Zea (1969), quien expone la hipótesis de la yuxtaposición; otros como Paz que no se asume en ninguna de las anteriores manifestado en obras como $E l$ laberinto de la soledad (1998), donde señala que la identidad es un proceso sin fin donde los mexicanos sólo se han colocado máscaras.

Para otros, la discusión sobre la identidad ha dejado de tener peso, por cuanto la globalización minimiza la importancia de las micro - identidades. "En el mejor de los casos se podría concebir la identidad latinoamericana como abigarrada y cambiante, 'una identidad heterogénea e internamente conflictiva', en la cual coexistirían varios ejes y sub-identidades en conflicto" (Vergara; Vergara y Gundermann, 2010). 


\section{Raúl García Palma}

Telos Vol. 20, No. 1 (2018). 159-198

En la investigación venezolana que se ocupa del discurso escrito sobre América Latina y el Caribe, se presenta la búsqueda de la profundización del código sociocultural de la identidad, es el caso de la obra Agentes de su libertad. Esclavos, sujetos y discursos en un Caribe que cambia (1790-1800) de la Profesora Dávila (2010), el mismo fue Premio Internacional de Investigación sobre la Emancipación, allí indaga sobre los discursos de la sociedad esclava del Siglo XVIII de Europa, el Caribe y la Provincia de Venezuela. Su apuesta por un sujeto de la historia que no es considerado para caracterizarla, de allí que haya sido excluido de ésta, amerita de justificaciones e incluso de posibles enunciados metafóricos, los mismos se acompañarán de los conceptos que surgieron desde el marco teórico de esta investigación y que se ven reflejados en la mecánica empleada por la investigadora Dávila, por ser una problematización sobre Latinoamérica y el Caribe que ella despliega de forma novedosa, donde se exponen componentes fundamentales del imaginario de la región; también es una reflexión sobre el alcance del mestizaje; y defiende la existencia de posibles ciclos en la historia de la cultura de Latinoamérica y el Caribe.

Se reflexiona sobre cinco tesis que a lo largo del texto de Dávila, irán hilvanando un argumento contrariando al modelo, siguiendo a Swaan (Ibáñez, 2007), ha orientado el sentido del discurso. Se inicia con un esclarecimiento y ubicación en el tiempo abordado por su libro, al enunciar el proceso denominado emancipación, éste ha sido evaluado en los últimos años desde diferentes dimensiones.

Pese a ser un delicado período de transición sociocultural, en el cual tradicionalmente la historiografía ha considerado la formación de ciudadanías, representaciones políticas y el constructo de la nación como centro nodal que dará cuerpo a las identidades, pertenencias y territorialidades de esos nuevos ciudadanos, una mayoría de esos estudios no ha considerado a los sectores marginales de la sociedad como parte integrante en la formación de la nacionalidad (Tesis D Nro. 1, p. 13). 
Antecedentes y temáticas de la investigación universitaria venezolana sobre Latinoamérica y el Caribe

Siguiendo el Modelo de Swann reconstruido desde esta investigación, el Modelo Actual -1, presentado por la profesora, es una historiografía que no considera importante para su consolidación y el de la identidad que dice interpretar, a los sectores marginales de la sociedad de esa transición sociocultural. La causa de esa invisibilización histórica es la discriminación social de las ciencias, la intención en un primer momento es posibilitar la entrada de la cultura del imperialista en la región, en este caso se inicia con la "descalificación de las producciones de las culturas precolombinas, primero, y de los criollos y mestizos, más tarde, así como de la naturaleza americana" (Saladino, 2010, p. 179). En cambio, el Modelo en búsqueda de integración que presenta Dávila, intenta generar valorización en las acciones de los esclavos como sujetos de ciudadanía. Este último planteamiento de lo ciudadano desde un sujeto excluido, demostraría que la nacionalidad surge no sólo desde la visión de la clases hegemónicas, tampoco desde el sistema de interpretación diseñado por esta misma clase, sino de la pluralidad étnica o lingüística, esta acción implica una revisión histórica, “... un reto epistemológico, gnoseológico, ético y político para las humanidades y las ciencias sociales y humanas en general, para la historia de las ideas y para la filosofía en particular"(Quintero-Montilla, 2009).

Las necesidades surgidas en la relación amo-esclavo de la época preemancipación americana, determina la recolección de información de los actos realizados por los esclavos para ganar espacios, donde los privilegios de los blancos se convirtieron en meta para medir "un avance social". Esta recolección de información, se convierte en el modelo integrado textual, porque de esa forma lo hace la ciencia histórica, lo que cambia es el sujeto.

Aunque imperaba el principio de la exclusión natural en esos discursos letrados y élite europea y de la sociedad colonial venezolana, que sentían la necesidad de separar de su entorno a negros y pardos, desde esos sectores bajos y medios se generaron estímulos para blanquear su piel como una nueva forma de amalgamiento y estrategia de ascenso, que lo podían posicionar en otros entornos sociales del color y de la calidad social. (Tesis D Nro. 2, p. 24). 


\section{Raúl García Palma}

Telos Vol. 20, No. 1 (2018). 159-198

A la pregunta de identidad ¿quiénes somos? los esclavos se proyectan en sus amos y responden "quisiera ser como ellos" y esa actitud va a formar grados diferentes en el Caribe, donde uno de sus polos será el cimarronaje. En esta gradación de alienación social, Dávila pone de manifiesto a través de dos tácticas autorales, éstas son las: a) maneras de los códigos socioculturales para convertirse en enunciado y b) principio para formar parte del archivo cultural. Ellos son el de la identidad y el de la colonización, este último desde la táctica autoral tema con historia.

Desde la colonización se han ido tejiendo en el Caribe, diversas posturas sociales que redundan aún en la vida de sus pueblos y que expone la autora, uno de ellos las estrategias de la invisibilización del proceso creativo para lograr los posibles alzamientos de indígenas y descendientes africanos. Por medio de la descalificación, surgida de la actitud de los religiosos católicos, quienes consideraban débiles a ambas etnias y que autores como Brathwaite, denominan: ignorancia de la educación letrada. A pesar de esta "ignorancia", se alza una contracorriente (Olivares, 2012), que fue motivo de un gran miedo por el otro. El miedo por los alzamientos que hubo a lo largo de los Siglos XVII y XVIII, hicieron que la legislación indiana ejerciera un control desmedido de utilización de armas y disminución de las potencialidades de la clase excluida del aprendizaje de la lectura, sin embargo, los temas de liberación, que se imbuían de la revolución francesa y de los alzamientos de esclavos tenían otras maneras de llegar.

Pese al despliegue controlador, era un hecho que ciertas 'desobediencias' ya eran difíciles de contener por más que los dueños intentaran detenerlas. Aunque las canciones, compuestas por 'ilustrados, que sensibilizaban sobre una 'patria' y una 'libertad', sobre un 'pueblo' y una 'soberanía' parecían desconocidas y ajenas al entender sencillo de los esclavos, otros contenidos más realistas para ellos, como 'mueran los opresores y sus partidarios', 'tirano', 'malvado', 'opresión' y frases como 'todos nuestros derechos son usurpados'. Sí surtirían efectos directos, porque dialogaban de modo natural con lo que había sido su realidad dentro de un desigual marco social que, sin elección, les había tocado vivir. (Tesis D Nro. 3, p. 62). 
Antecedentes y temáticas de la investigación universitaria venezolana sobre Latinoamérica y el Caribe

Para la autora, el diálogo entre productos culturales y realidad vivida, alimenta a la denominada cultura de la resistencia que, en algunos autores del marco teórico de esta investigación, es una temática que gira en torno de la colonización, pero la misma se ha resignificado acercándose al acto de insubordinación más combatido que se denominó el cimarronaje. Éste como resistencia, se ha desplazado en el imaginario de la región, también en abrir espacios que se cerraron con la ideología colonial y que, al traerlos como lo ha trabajado Dávila, se intenta desmontar. Así hay códigos socioculturales, como el de cultura de la colonización, que, entre sus temáticas, sigue generando tensiones para a través de su problematización de la historia, tener nuevos significados. "Actualmente la noción de cimarrón/na es resemantizado y utilizada en el discurso de las organizaciones afrodescendientes para definir sus prácticas actuales de lucha y resistencia activa y pasiva" (Ayala y Mora Queipo, 2008, p. 26). Además de la habilidad de emprender espacios de organización, el marco de la "diversidad dialógica" (Morán Beltrán, 2006, p. 73), donde está la formación discursiva del discurso escrito sobre América Latina y el Caribe, a la que pertenece Dávila, el denominado en esta investigación como Ciencias Integrales, etapa histórica que permite aclarar que la debilidad constituida por la admisión del estado de paternidad por otras clases de los indígenas y afroamericanos, no era tal.

$\mathrm{Al}$ exponer la existencia de una figura a la que se dirigían los esclavos, como el denominado procurador de pobres, quien comenzó a enfrentarse al procurador que defendía a los intereses de la Corona y de las clases blancas, también Dávila expone un cambio en la manera de hacer el pensamiento que prevalecía, como era que lo afrodescendientes esclavos no tenían, no sólo derecho a defenderse, sino que no lo podían hacer porque eran débiles, en cuanto a pensar y concretar ideas. Dávila sugiere, la existencia de pensamientos encontrados y a partir de éstos, en cuanto a ver o entender a los excluidos sociales, se hace la pregunta “... ¿no nos hablan, acaso, de un cambio en la concepción que se tenía del Derecho para la época?” (Tesis D Nro. 4, p. 93). 


\section{Raúl García Palma}

Telos Vol. 20, No. 1 (2018). 159-198

Cambiar la historia, incluso resignificándola como proceso, que no sólo muestra que las facultades teóricas-prácticas para diferenciar sujetos, pertenece en el discurso escrito sobre la región latinoamericana y caribeña, a la etapa denominada en esta investigación: ciencias integradas, que está bajo desarrollo y que permite definir que un sujeto creador e impulsor de las modalidades argumentativas del espacio de defensa por los derechos en la colonia. La modalidad de aclarar la historia, en favor de los silenciados surge en Dávila, al utilizar como táctica autoral: la profundización en el imaginario latinoamericano y caribeño.

Al ser el discurso, interacción social “... porque los significados se crean, se retan, se transforman, mueren y renacen en sociedad y no en compartimientos aislados fuera de contexto" (Bolívar, 2007, p. 22), entonces los significados, son parte de negociaciones y disputas en lo real y tienen su mayor efecto en el imaginario. Diversos autores han incidido en los desplazamientos de los códigos socioculturales, buscando una reacomodación de la realidad, tratando de eliminar zonas álgidas con conocimientos y saberes que la describen y “... delimitado la realidad cultural de nuestro continente a partir de nociones como las de alteridad, mestizaje, transculturación, colonización, eurocentrismo, concientización, entre otras; categorías que dan cuenta de esa forma de pensar que caracteriza el narrar del intelectual latinoamericano..." (Hernández, 2008b, p. 47).

Estos conocimientos y saberes sobre la realidad cultural, permite la negociación de la actitud "el otro sabe que existes, porque tienes prácticas de creación", además de este pensar es imprescindible: a) disminuir los condicionamientos históricos en que se han mantenido las etnias marginadas de la historia; b) su reconocimiento para aplicar quizás la memoria sanadora (QuinteroMontilla, 2011) y c) conocer las zonas álgidas que producen obstáculos para que el sujeto latinoamericano y caribeño pueda ejercitar sus saberes. Las zonas álgidas son aquellas donde predominan condicionamientos, que se reflejan en los documentos 
Antecedentes y temáticas de la investigación universitaria venezolana sobre Latinoamérica y el Caribe

escritos, a lo largo del diálogo en la red que sostiene el discurso escrito sobre América Latina y el Caribe, pero también en otros espacios culturales.

En la industria cultural se da una de las mayores zonas álgidas “... que condicionan las acciones afirmativas de los afrodescendientes y su desarrollo social, tanto a nivel nacional como internacional. Es común que se apropie de sus productos culturales y los inserte en el mercado tendiendo a vaciarlos de su contenido identitario y de resistencia étnica" (Ayala y Mora Queipo, 2008, p. 20). Aspectos resaltados como los de la investigación de Dávila, sirven para exteriorizar los productos culturales de las minorías y develar los mecanismos de invisibilización en el campo ideológico de tensiones, muy cercano a los estudios subalternos.

La investigadora Dávila de igual forma recuerda, en un apartado especial de su libro, que, en la historiografía sobre la cultura de la región, la escritura sobre develaciones e invisibilizaciones de sectores excluidos, es acompañada de otras expresiones culturales.

En la misma época, y en el espíritu de darle relevancia a otras expresiones culturales que en América Latina se manifestaron también por lo negro y la negritud, recuérdese que para este período de los setenta hubo una efervescencia musical latina, caribeña y salsónoma, expresada en el boom musical de la FaniaAllStars y Gran Combo de Puerto Rico, entre otros. Para un público lector masivo, en muchas de sus letras estos grupos denunciaban el rescate del elemento negro como parte de la identidad cultural del Caribe hispano. En este sentido, así como los discursos historiográficos nos ayudan a pulsar el tiempo, las expresiones de la cultura musical escrita también son resortes para pulsar las manifestaciones más populares que se expresaron en esos momentos por la problemática de la negritud (Tesis D Nro. 5, pp. 111112).

En las formaciones discursivas del discurso escrito sobre América Latina y el Caribe, se asumen todos los tipos de escritura que determinan su identidad cultural, estos tipos escriturales caracterizan lostextos de investigación universitaria venezolana sobre el tema,dándole sentido a sus temáticas y códigos socioculturales, con ellos se hace posible verificar situaciones que conforman la memoria de esta región. 


\section{Raúl García Palma}

Telos Vol. 20, No. 1 (2018). 159-198

\section{Regionalidadsobre Latinoamérica y el Caribecomo productora de imaginarios} sociales

El viaje que se establece dentro de la preocupación por la identidad latinoamericana y el Caribe, va desde una "ciudad letrada", metáfora de una región cuyos intelectuales se asumen a partir de la mirada foránea, a la "ciudad crítica" donde se presenta una narrativa de la historia, con un sujeto que impulsa el pensamiento crítico de la historicidad (Hernández, 2008b). La identidad de esta regionalidad, desde el sujeto crítico de la historia, presenta imaginarios, entendiendo éstos como imágenes que pueden estar conformadas por iconos como los presentados en..." la iglesia de Tonanzintla en Puebla. Es ella un ejemplo de síntesis de imágenes, en que aparecen ángeles emplumados, profusión de flores polícromas y bandejas con frutas exuberantes" (Noel, 2004). Esta estética dentro del texto escrito, que es lo interpretado por esta investigación, se soportaría sobre imaginarios que inician o fundan una nación o en su defecto cultura(s). "La nación es 'imaginada' porque... los integrantes ni siquiera... conocerán nunca a la mayoría de sus compatriotas... a pesar de lo que 'en la mente de cada uno vive la imagen de su comunión'" (Mellado, 2008). Las imágenes son amplias en su significado, pero son el inicio de puntos comunes que luego se denominarán intersubjetividad.

En el texto que a continuación se interpreta denominado Independencia y emancipación. Élites y pueblo en los procesos independentistas hispanoamericanos, del Profesor Acosta (2010), que fue Premio Internacional de Investigación sobre la Emancipación, la intersubjetividad de la región que luego se denominará Latinoamérica y el Caribe, presenta la imagen de la violencia entre clases sociales que a través de cinco tesis se opone a los modelos que han tratado el código sociocultural centrado en la independencia, con métodos de interpretación de otras realidades y de "lecturas sesgadas" que pasaron a constituir la historia oficial. La causa de una historia oficial, es que fue hecha por la clase social hegemónica que quedó en el espacio de poder dejado por el imperio colonial y la misma, sacó provecho con la intención de dejar intacto la visión colonial de la esclavitud y el error de interpretar los 
Antecedentes y temáticas de la investigación universitaria venezolana sobre Latinoamérica y el Caribe

hechos independentistas, como si no estuviesen relacionadas de manera directa con las revoluciones burguesas. El modelo expuesto, se sintoniza con una postura comprometida con el reto epistemológico de impulsar o fortalecer el pensamiento crítico sobre Latinoamérica y el Caribe o en su defecto, con la epistemología de concebir otra forma de ver la historia; es lo que algunos autores dentro de una emergencia de saberes en relación al territorio y el poder donde emerge, categorizan como alternativa a la unicidad de la razón occidental. Es lo que Aníbal Quijano nos reveló... “en las profundas conexiones de lo que llamó la colonialidad del saber y del poder" (Porto-Goncalves, 2009). La práctica de este pensamiento crítico, se observará en las siguientes tesis.

Los criollos no necesitaban emanciparse, puesto que eran libres... Los que querían emanciparse eran los pardos, los indios y sobre todo los negros; no los criollos. Lo que estos llaman emancipación se refiere en todo caso a emanciparse del dominio español... que es uno de los significados limitados de emancipación. Pero la verdadera emancipación es la otra, la de los explotados, emancipación que los criollos, salvo una minoría, lo más revolucionarios como Bolívar o Artigas, no conceden, no están dispuestos de ninguna manera a conceder porque atentaría contra su propia dominación (Tesis A Nro. 1, pp. 26-27).

En el imaginario social latinoamericano y caribeño, la imagen de un héroe que era capaz de ceder su dominación está limitada por lo que la historia oficial narra. Al surgir cambios en la red de Formaciones Discursivasrelacionado con el discurso escrito sobre Latinoamérica y el Caribe (Ver Cuadro Nro. 1), más allá de las ciencias sobre América Latina y el Caribe y se aproxime a la denominada ciencias de América Latina y el Caribe, los límites históricos comienzan a resignificarse. La diferencia entre ciencia sobre y ciencia de, es su trascendencia en el manejo de los signos, cómo lo maneja una y cómo se entiende en otra, en el paso de una a la otra, sería la llegada o antecedente a la "ciudad crítica". 


\section{Cuadro Nro. 1.}

Visualización de la red de Formaciones Discursivas del discurso escrito sobre Latinoamérica y el Caribe

\begin{tabular}{|c|c|c|c|}
\hline \multicolumn{4}{|c|}{ Red de Formaciones Discursivas } \\
\hline Antecedentes & Ciencias Positivistas & $\begin{array}{c}\text { Ciencias Positivistas } \\
\text { con Teorías } \\
\text { Regionales }\end{array}$ & Ciencias Integradas \\
\hline \multirow{4}{*}{$\begin{array}{l}\text { Pensamiento } \\
\text { Latinoameric } \\
\text { ano y } \\
\text { Caribeño }\end{array}$} & $\begin{array}{c}\text { Sociología en } \\
\text { Latinoamérica y el } \\
\text { Caribe } \\
\end{array}$ & $\begin{array}{c}\text { Sociología } \\
\text { Latinoamericana y } \\
\text { caribeña }\end{array}$ & \multirow{4}{*}{$\begin{array}{l}\text { Estudios Culturales y } \\
\text { Subalternos sobre } \\
\text { América Latina y el } \\
\text { Caribe }\end{array}$} \\
\hline & $\begin{array}{c}\text { Filosofía en } \\
\text { Latinoamérica y el } \\
\text { Caribe }\end{array}$ & $\begin{array}{c}\text { Filosofía } \\
\text { Latinoamericana y } \\
\text { caribeña }\end{array}$ & \\
\hline & $\begin{array}{c}\text { Psicología en } \\
\text { Latinoamérica y el } \\
\text { Caribe }\end{array}$ & $\begin{array}{c}\text { Psicología } \\
\text { Latinoamericana y } \\
\text { caribeña }\end{array}$ & \\
\hline & $\begin{array}{c}\text { Historia en } \\
\text { Latinoamérica y el } \\
\text { Caribe }\end{array}$ & $\begin{array}{c}\text { Historia } \\
\text { Latinoamericana y } \\
\text { caribeña }\end{array}$ & \\
\hline
\end{tabular}

Fuente: Elaboración propia.

En estos desplazamientos de resignificación, el héroe no es un individuo, sino actores con más carga semántica como "pueblo" o "minoría". Su acción más significativa, es el compartir los intereses de los otros y reconocerlos desde una regionalidad que se puede denominar nación, donde hay un "nosotros" preparándose para otro tipo de alteridad. La alteridad del pensamiento crítico desmonta la historia ¿con cuál intención? ¿qué nuevo sistema de interpretación sobre lo latinoamericano y el Caribe se propone?

Dos importantes elementos a señalar son: el primero, que en estas conspiraciones elitescas el pueblo no aparece por ninguna parte, y el segundo, que en esta oportunidad los pardos caraqueños por medio de varios oficiales de milicias condenan la conspiración mantuana... y más allá de cualquier manipulación de estos en tal sentido- muestra la profunda desconfianza de la población parda respecto de la oligarquía criolla. (Tesis A: Nro. 2, p. 100).

Las ciencias de América Latina y el Caribe producen imaginarios sociales, es decir imágenes que van a darle fuerza a los códigos para que orienten a la sociedad, en 
Antecedentes y temáticas de la investigación universitaria venezolana sobre Latinoamérica y el Caribe

el fragmento anterior refieren al momento cuando surgen los hechos de independencia en la región, la ausencia de pueblo se superpone a la presencia de la oligarquía, el sentido que se genera es que existió la desconfianza entre clases al surgir las naciones, lo que hizo casi imposible un proyecto nacional.

La otra imagen que alimentará el imaginario social de América Latina y el Caribe, es otra ausencia, el de las revoluciones de los pobres, la misma habrá de hacerse contra las oligarquías que apostaban por la epistemología de la modernidad que negaba el "nosotros" de la región, lo que convirtió a estas revoluciones ausentes en las únicas defensoras de la gran regionalidad. Las ciencias de América Latina y el Caribe tendrán como códigos socioculturales aquellos que surgieron de las imágenes que se refieren a la ausencia de una clase, con preguntas como ¿qué buscaba y animaba a esta clase? Es también lo que alienta a estas ciencias como sistema de interpretación, el ir contra una visión europea como única y posible de vivir y no contra una visión europea del quiénes somos, como la utopía y paisaje exótico. No es como lo afirman ciertos críticos literarios, cuando caracterizan una generación como transterrada por querer vivir más allá de las fronteras de la región y poder decirle al mundo "somos como ustedes", como obsequiando la alteridad. Los "territorios flotantes" de los nuevos escritores latinoamericanos apuntan más hacia la asimetría de la razón occidental, tanto que son territorios para ser fijados a la "ciudad crítica". Habría que desmontar afirmaciones como la siguiente: "En todo caso, se trata de evitar ser latinoamericano como se espera que se debe ser para satisfacer el imaginario europeo: lejos de los tópicos y clichés con que siempre se lo ha caracterizado" (Ainsa, 2010, pp. 58-59). Uno de los criterios principales, dentro de la formación discursiva del discurso escrito sobre América Latina y el Caribe, denominado en esta investigación ciencias integradas, es el evitar ser latinoamericano y caribeño desde la razón europea, porque existen territorios flotantes de su historia aún no explorados. Territorios abandonados como imágenes y códigos, donde la clase que ha excluido de la historia a la revolución de los pobres, todavía se moviliza como tal. Así el 


\section{Raúl García Palma}

Telos Vol. 20, No. 1 (2018). 159-198

investigador Acosta señala en el proceso independentista del Perú, a una clase que se vio forzada a tomar decisiones para hacer surgir su alteridad histórica.

No hay lucha revolucionaria, y la independencia le es impuesta casi a la fuerza desde afuera, por argentinos, chilenos, venezolanos y neogranadinos; mientras los mediocres e incapaces líderes peruanos, que pasan por patriotas, traicionan a los libertadores: primero a San Martín, que fracasa en lograr una independencia que apenas puede proclamar, y luego a Bolívar, que -con Sucre- es quien finalmente libera al Perú, cosa que casi se niega a reconocerle esa oligarquía mezquina, lo mismo que sus herederos (Tesis A Nro. 3, pp. 165-166).

La alteridad, al ser una profundización en la búsqueda de diferenciación con el otro, tiene una historia negativa que no la hace posible para algunos de los actores que se quieren convertir en hegemónicos y por otra, quien vive en la hegemonía no asume que debe ceder para cambiar y que el otro se humanice, porque en la humanización del otro está también la del que cede.

La alteridad como parte esencial del discurso escrito sobre América Latina y el Caribe, también viene presentando otra negatividad en cuanto a su espacio teorético, al presentar transcendencia en las denominadas ciencias positivistas sobre y desde la región, a las ciencias integradas. En éstas se debate, el locus dónde se arman las prácticas discursivas, este lugar o locus en los últimos veinte años, ha sido dividido por el concepto de latinomericanismo de primer y segundo orden (García Palma, 2013), que para esta investigación, el primer orden, es aquel espacio donde están los antecedentes de las ciencias sobre la región y ciencias positivistas sobre/en la región, en el segundo orden están las ciencias integradas. La diferencia mayor entre unos y otros, es que los segundos son los interpretantes metropolitanos (investigadores universitarios o de centros de investigación), que enuncian teoría sobre la región, es decir a los interpretantes que viven dentro de la región se les niega esa categoría, sin embargo, a esa negatividad le intenta dar respuesta en su momento Spivak, con una noción cercana al sujeto trascendental alternativo de Roig y Hinkelammert (Acosta, 2010). 
Antecedentes y temáticas de la investigación universitaria venezolana sobre Latinoamérica y el Caribe

El que interpreta sabe que lo hace desde una perspectiva en particular, aunque utilice para ello categorías metafísicas como 'libertad', 'identidad', 'diferencia', 'sujeto', 'memoria colectiva, 'nación, 'derechos humanos', 'sociedad', etc. Lo importante aquí no es la referencialidad ontológica de tales categorías — que en opinión de Spivak no son otra cosa que "prácticas discursivas"— sino su función performativa. Lo que se quiere no es encontrar una verdad subyacente a la interpretación sino ampliar el campo de maniobralibidad política, generando para ello determinados "efectos de verdad". (Castro-Gómez y Mendieta, 1998, p. 15).

En el nivel de las Ciencias Integradas en la red del discurso escrito sobre América Latina y el Caribe, la reconstrucción de la identidad a partir de este sujeto y este nivel de la ciencia que intenta interpretar o decir algo sobre ese espacio, debe tener presente no sólo un sistema de representación. También su relación del contexto, donde se intenta configurar conceptos, ideas, acciones, silencios. "Procesos estos que se relacionan dialécticamente a partir del sistema de representaciones (aspectos ideales de la cultura) y del sistema de manifestaciones (aspectos materiales de la cultura)". (Bigott, 2007). La reconstrucción de la identidad a partir del sujeto trascendental alternativo, debe tener claro que “... el discurso es acción porque con las palabras se construyen y transforman las realidades (Bolívar, 2007, p. 22).

Hasta el nivel de Ciencias Integradas, las prácticas discursivas escriturales, eran para ser expuestos los modelos integrados textuales sobre la cultura, a partir de su discusión e inicio, la función performativa señala: a) un horizonte de maniobrabilidad política que debe tener toda acción dentro de la práctica discursiva y b) los modelos integrados deben apuntar con hallazgos, los efectos de verdad, en el sistema de manifestaciones. La alteridad desde el sujeto trascendental alternativo, surge de la disminución en las negatividades de los niveles del discurso escrito sobre América Latina y el Caribe, por una parte utiliza las categorías metafísicas de los subalternos de la modernidad y las reacomoda, continuando una práctica que, de manera aparente, surgió en los países del primer mundo y por otra, construye la función performativa 


\section{Raúl García Palma}

Telos Vol. 20, No. 1 (2018). 159-198

aclarando, incluso, situaciones de la historia como lo enuncia Acosta, de la independencia mexicana.

Es por ello el único proceso independentista hispanoamericano en el que se funde realmente, aunque por desgracia solo en esta fase, la lucha por la independencia con la lucha por la emancipación y con predominio claro de esta última sobre las limitaciones excluyentes y elitescas de la primera (Tesis A Nro. 4, pp. 177).

La función performativa del concepto emancipación se ha proyectado al horizonte de maniobralibidad política, aquí es donde se devela “... la analogía (¿a qué se parece la experiencia?) (Ray, 2003, p. 152), en la actualidad en los diversos países de la región, reconocerse desde la independencia o asumir qué le falta para llegar a la emancipación, determina un cruce de reivindicación de personajes como Simón Rodríguez, quien asomaba ese significado porque “... constituir pueblo significa eliminar el populacho, el vulgo, la gentuza, todas las formas diferenciales de existencia del pueblo". (Ortega, 2011, p. 44. También se reivindican tácticas de resistencia, que la historia oficial ha silenciado.

Y lo más original de todo esto es que la participación popular en la lucha de independencia boliviana asume pronto $-\mathrm{y}$ mantiene por muchos años, en un caso hasta entroncarse con la etapa final de la independencia- la forma de lucha guerrillera, de guerra de guerrillas, siendo esta la lucha guerrillera y estas guerrillas (por lo general ignoradas o despreciadas por la Historia oficial boliviana) no las únicas, pero sí las primeras y las más importantes de toda la gesta independentista hispanoamericana (Tesis A Nro. 5, p. 183).

El debate entre memoria y autoreflexión de la historia. (Sorgentini, 2003), como quiebre, es donde también se sintoniza el sujeto trascendental alternativo como un código sociocultural autoreflexivo, éste permite afirmar que en las investigaciones donde se introduce este debate, como lo hace Acosta entre independencia y emancipación, surge otra arquitectura cognitiva como epistemología. Es otro marco de diálogo como elemento de los discursos porque: a) existe un planteamiento político diferente como tácticas autorales, al argumentar bajo el principio que estas culturas 
Antecedentes y temáticas de la investigación universitaria venezolana sobre

Latinoamérica y el Caribe

han estado siempre bajo el signo de la colonialidad (Yehia, 2007) y b) con él se revisan los actores y el centro de esta metaflexión, es develar si el interpretante cumple la función performativa en su hacer.

\section{La memoria colectiva en la identidad regional sobre Latinoamérica y el Caribe}

Dentro de un amplio espacio denominado América Latina y el Caribe, que se trata de contener focalizando su existencia en el discurso escrito que lo nombra y hace posible el compartirlo, está el usuario de los códigos referenciales, éste se devela como el sujeto americano para algunos autores (Fernández-Nadal, 1999) y el sujeto latinoamericano para otros, que ha ido constituyendo en varias líneas históricas, de allí su multidiversidad y heterogeneidad de saberes.

De esta manera, la Historia de las ideas en América Latina en su intrínseca asociación con la filosofía latinoamericana, constituye visiblemente un saber normativo, de afirmación y constitución de un sujeto colectivo, que provisoriamente podría identificarse como sujeto latinoamericano, cuya afirmación y constitución no es ni lineal, ni homogénea, ni continua, sino conflictiva, heterogénea y discontinua, por lo que toca a la Historia de las ideas en América Latina el relevamiento y recuperación de comienzos y recomienzos del pasado, como lugares de afirmación para nuevos comienzos y recomienzos, en una perspectiva instituyente abierta hacia el futuro como proyecto de auténtica y renovada identidad. (Acosta, 2009, p. 38).

Ese sujeto colectivo ampliado por circunstancias geopolíticas al espacio de El Caribe, recomienza como proyecto desde la escritura que lo convoca, en cada nivel de la red del discurso escrito. Allí se ha ido concretando un código sociocultural como es el de sujeto trascendental alternativo, cuyas características predominantes es tener una postura crítica frente a planteamientos como: “... la 'muerte del sujeto' o su fragmentación en la posmodernidad y en la globalización” (Acosta, 2010, p. 27). El discurso escrito sobre América Latina y el Caribe, complementa su hacer de caracterización, reflexión y análisis, con ámbitos que desplazan su interés sobre la región como son la Historia de las ideas en América Latina acompañada no sólo con la filosofía latinoamericana. También en ese acercamiento académico, todo lo que se 


\section{Raúl García Palma}

Telos Vol. 20, No. 1 (2018). 159-198

autoproclama y adjetivisa como de América Latina y el Caribe, predispone su cuerpo de búsqueda dándole sentido al sujeto trascendental alternativo.

El que el corpus reflexivo en la red de formaciones discursivas sobre el discurso escrito de la región, no se limite a lo que las ciencias positivistas o las ciencias positivas con teorías regionales (Ver Cuadro Nro. 1), consideran como situaciones denominadas de acción social, sino que se amplíe a las zonas dondese constituye la subjetivación, como aquellos conceptos que describen circunstancias únicas de una cultura. Esa subjetivación si la enmarca las ciencias integradas, que denuncian el afán del yo universal cartesiano, apostando por un sujeto que se ajusta contra la globalización y su vivencia. Este planteamiento de un yo universal descarnado lo había definido Césaire, desde las experiencias colonizadoras de El Caribe. "El concepto 'descarnado' es aquí crucial. Para Césaire, el universalismo abstracto, es aquél que desde un particularismo hegemónico pretende erigirse en diseño global imperial para todo el mundo..." (Grosfoguel, 2007, p. 71). El ir en contra de ese particularismo en todos los espacios, ahora es parte de las ciencias integradas como asalto epistemológico y así también lo concibe, la Profesora María del Pilar Quintero en su libro Sueños y palabras de América Latina (2008).

En el estudio del pensamiento latinoamericano surge como un asunto de particular importancia la formación del sujeto latinoamericano, su subjetivación y constitución.

La relación entre el desarrollo de un pensamiento propio, en este caso un pensamiento latinoamericano, y el proceso de subjetivación de un sujeto latinoamericano ha sido estudiada por diversos investigadores y de manera fundamental por Arturo Roig. Este filósofo ha hecho énfasis en la importancia y la necesidad de estudiar la literatura latinoamericana, y en espacial la novela, como manifestación de un sujeto latinoamericano. (Tesis Q Nro. 1, p. 17).

Es decir, el sujeto latinoamericano implica la transición que se inicia en el área de la investigación, cuando se procura un viaje desde la relación sujeto-objeto al de sujeto-sujeto. Involucra transitar por procesos como ir del sistema cognitivo a otro, donde se abarca al sistema afectivo (Guanipa, 2011). Es decir el investigador se 
Antecedentes y temáticas de la investigación universitaria venezolana sobre Latinoamérica y el Caribe

autoproclama con intereses, más allá de la ciencia, dentro de la cultura que trata de interpretar o investigar, de allí que se pueda nombrar como interpretante (García Palma, 2013), que interpreta y luego pasa como contenido de lo que interpretaba. El sujeto entra en un proceso, que al estar interpretando reconoce su transformación, que la ciencia positiva no ha sabido recolectar, sino las disciplinas inter $y$ transdisciplinarias de las ciencias integradas.

La subjetivación es una cierta práctica a la cual los sujetos son inducidos desde la cultura, como la necesidad de un encuentro con uno mismo: el sujeto es inducido a observarse a sí mismo. Este proceso trae consigo una transformación de sí mismo. Esta relación consigo mismo, inspirada en los estoicos, no es una práctica que se agota en el sí mismo (Tesis Q Nro. 2, p. 21).

La autoobservación como parte del proceso de subjetivación, implica un reconocimiento contextual del momento donde se pide la "relación consigo mismo". El sujeto se observa en las acciones de una cultura que es suya y se reconoce en un nosotros histórico, donde existen intereses, valores, actitudes y creencias que no había observado en la ciencia. La mediación de la palabra se conjuga en el alejamiento de la ciencia para entrar en esos espacios subjetivos de las culturas en América Latina y el Caribe, tal planteamiento lo concentra un crítico como Rama (1985) en el tema: ciudad letrada, este código es temática del código sociocultural sujeto americano. La ciudad letrada está constituida por la escritura de leyes, normas, costumbres y una manera estética donde el nombrar y exponer una narrativa, es opuesta al vivir y al convivir de una mayoría silenciada. Para Rama, la ciudad letrada se convierte en un gran principio desde donde expone su obra: “... el desencuentro de ésta con ese entramado de lo social que el crítico denomina 'ciudad real' y que ubica siempre fuera de la textualidad de la escritura canónica e incluso de la polisemia literaria de la alta cultura (Pineda Franco, 2009, p. 120).

Para que la "ciudad real" comience a presentarse en la textualidad, es necesario que en el proceso de subjetivación donde la otra narrativa cultural, la que el sistema cognitivo no permite aparecer, se logre develar, se hace imperativo que: a) desde el 


\section{Raúl García Palma}

Telos Vol. 20, No. 1 (2018). 159-198

sistema afectivo se puedan dar transiciones que alcancen el reconocimiento por un sujeto regional, el mismo aún no conocía procesos para vivir su subjetivación y b) la imaginación pudiera incidir en la construcción de esa cultura regional, aspecto que Pilar Quintero reconoce y esboza en su libro.

Uniendo el planteamiento de Roig y el de Castoriadis, quien revaloriza desde la filosofía el papel de la imaginación en la construcción de lo histórico social, impulsamos la tesis de la importancia del discurso estético-literario como expresión del imaginario social, y por ello fuente de ideas, de gran valor para la filosofía de la cultura. Reflexiones e ideas que por las condiciones históricas encontraron como principal vía de expresión el discurso literario (Tesis Q Nro. 3, p. 21).

Según Roig y es uno de sus grandes aportes a la construcción del pensar sobre el sujeto latinoamericano, en la historia se presentan líneas de continuidad histórica, que son manejadas por los grupos que controlan la salida de sus imaginarios sobre la misma, pero se quedan silenciados episodios, como acciones secundarias respecto a una acción principal. Esos episodios, son difíciles de recoger y exponer desde la filosofía u otros registros considerados ciencia, para que se puedan convertir en referencia cierta para las diversas culturas que conforman lo latinoamericano y caribeño. “... Roig considera que la idea de una historia episódica para el trabajo historiográfico en América Latina es relevante puesto que permite... la búsqueda y descubrimiento o de miles de hechos que aparecen como episodios de períodos no bien establecidos" (Vignale, 2008-2009, pp. 163-164). Lo episódico, como aquellos hechos que van configurando restos y también, momentos esenciales de una cultura, se pueden establecer por medios como la literatura, que, construida con elementos de la imaginación, delinean actores que se dan en los contextos de los autores, pero que los convierten en visionarios de un sujeto histórico aún no previsto o no perteneciente a la secuencialidad ejercida por una clase hegemónica con un imaginario con característica de foraneidad.

Con la construcción del personaje SAB Gertrudis de Avellaneda elabora y propone un nuevo imaginario sobre el afroamericano, como sujeto histórico y se anticipa a otros autores que en el siglo XX aportarán una 
Antecedentes y temáticas de la investigación universitaria venezolana sobre Latinoamérica y el Caribe

nueva visión del afroamericano en particular, y del sujeto histórico latinoamericano en su carácter, pluricultural y multiétnico en general (Tesis Q Nro. 4, p. 86).

El imaginario latinoamericano y caribeño se abre desde la ficción a episodios silenciados por un letrado, que quiere construirse como par de Europa. La objetivación sobre la regionalidad de este imaginario había sido emprendida por el denominado pensamiento emancipador, luego y reñido con la filosofía que le niega su ámbito excluyéndolo, el ensayo como registro de lo real más cercano al imaginario develará un sujeto con conceptos para dar sentido a una narración cultural. De este transitar cultural, la ciencia positivista intentará medir esta narración como parte de la universalidad de la ciencia, hasta que se crean dentro de esta última teorías regionales con ánimo de globalidad: una de ellas la hibridez (García Canclini) o las mediaciones (Martín-Barbero), pero desde las experiencias de vidas en las urbes latinoamericanas. La interpretación y el análisis de los “... procesos de hibridación va a la par del de las mediaciones, pues ambos despliegan las distintas formas de producción simbólica. En las mediaciones es a través de la reapropiación cultural, y en la hibridación, de la mezcla cultural" (Espinosa y Arellano, 2010, p. 295). Quien da este salto en la relación entre formaciones discursivas del discurso escrito sobre América Latina y el Caribe, como es abrirse a otras formas de objetivación y establecerse con ello teorías desde la región, se desplaza de las ciencias positivistas y se convierte en el interpretante (sujeto de enunciación) del nivel de la relación denominado: Ciencias Positivistas con Teorías Regionales (Ver Cuadro Nro. 1), ese es la trascendencia sobre su anterior nivel y a su vez, es el reto que tendrá el nivel que le precede.

Los anteriores interpretantes buscaban representar con modelos foráneos y el acercamiento perentorio a una forma de objetivar: el ser o la acción social, pero quienes abren a otro tipo de formas de objetivación del mundo cultural lo hacen creando teorías donde el imaginario, también permite la narración cultural. Ahora esta teorización sobre la cultura de la región, es parte del interdiscurso de las formaciones discursivas escritural sobre América Latina y el Caribe. 


\section{Raúl García Palma}

Telos Vol. 20, No. 1 (2018). 159-198

Un enunciado, en tanto es una unidad constitutiva del discurso, se inscribe en una formación discursiva en relación con el interdiscurso. Un enunciado nunca se repite de la misma manera porque su función enunciativa cambia de acuerdo con sus condiciones de producción. A partir del análisis de los enunciados presentes en un texto se pueden identificar las diferentes posiciones asumidas por los sujetos del discurso (Hall, 2010, p. 197).

La ciencia con teorías regionales contendrá enunciados presentes con sentidos diferentes de otra formación discursiva. En cada formación discursiva de la relación del discurso escrito regional, a la pregunta ¿cómo representar al sujeto latinoamericano y caribeño? Se tratará de teorizar de diversas maneras, pero en todas las respuestas, parece insistir una característica que envuelve al sujeto y la da sentido dentro de la pregunta como objeto de representación. Como objeto debe haber algo que permita su caracterización permanente, lo latinoamericano y caribeño como interdiscurso al que todas las formaciones discursivas nutren o debilitan, deslegitiman o legitiman. Para Roig y Quintero la fortaleza es buscar en el imaginario, pero allí la construcción del sujeto pasa por lo que configura.

La filosofía latinoamericana de Arturo Roig, quien viene insistiendo en la necesidad de revisar la historiografía filosófica oficial y ampliar la búsqueda de las fuentes del pensamiento latinoamericano a otros discursos, como el político y el literario, que sin ser estrictamente filosóficos, son portadores de ideas y experiencias sociales, propias de la existencia social y cultural latinoamericana y por ello, son imprescindibles en la construcción del pensamiento y la representación del sujeto social de América Latina (Tesis Q Nro. 5, pp. 130-131).

Para interpretar lo que configura, determina y permite el interdiscurso de ese sujeto social, se puede argumentar con Peirce, cuando "subraya que no es nada parecido a una 'cosa', sino algo encarnado en el objeto como un hábito, una 'regla de acción', una disposición, un potencial real, o una permanencia de alguna relación" (Charbel, 2007). El sujeto latinoamericano y caribeño se trasluce porque pervive en una relación de naciones con historias parecidas que las convierte también en culturas, 
Antecedentes y temáticas de la investigación universitaria venezolana sobre Latinoamérica y el Caribe

con necesidad de colocar en diálogo "el otro sabe que existes, porque tienes prácticas de creación" como principio de integración y como política que, para Roig, es parte de su representación, en el próximo punto a través de dos textos, se profundizará en el para qué ese sujeto busca integrase.

\section{La búsqueda de legitimación de las discusiones sobre los códigos socioculturales para caracterizar a Latinoamérica y el Caribe}

Sin conocimientos y saberes no puede haber memoria colectiva, por ende, no habría conceptos para el recuerdo que es la manera inmediata de afirmar que hay identidad. No hay certeza de hablar sobre un Yo cultural que se refleje en un "Nosotros", el conocimiento o los saberes cuando se amplía su significación a las tecnologías del pueblo, se niega al oponérsele el discurso imperial. Éste lo tachará como utopía, es decir la tierra prometida del bien que ellos no han logrado alcanzar y donde prevalece la inocencia, que con el tiempo pasará a convertirse en "pueblo a ser orientado" por estar en una etapa menor; el discurso imperial también lo puede caracterizar como distopía. (Alonso et al, 2005), lugar aciago o peligroso y que merece la guerra para ser domado. Desde esta negación de memoria es que se inicia la interpretación de uno de los libros que en este punto se despliega desde sus sentidos, el primero de ellos, por medio de tres de sus tesis, el libro del Profesor Jesús García, Caribeñidad (2007), en el mismo se constata la descalificación donde se ha mantenido la región desde los inicios de los procesos imperiales, proceso que se divide en varias vertientes: la descalificación política, la cultural y de la naturaleza.

No compartimos el criterio del historiador Pedro Manuel Arcaya cuando en su análisis sobre esta insurrección cercana expresaba que este hecho obedecía a 'impulsos inconscientes'. Para nosotros se trataba de un hecho totalmente consciente, organizado y con aspiraciones libertarias frente a la discriminación, el maltrato físico y moral que sufrían los negros libres y esclavos de aquella región... (Tesis G Nro. 1, p. 46).

En el fragmento anterior, se observa un ejemplo de descalificación cultural, presentada como tesis en el texto del Profesor García. En el mismo se relata las 


\section{Raúl García Palma}

Telos Vol. 20, No. 1 (2018). 159-198

diversas insurrecciones de los esclavos en la colonia y su relación, con lo ocurrido en Haití (1791), acción que se califica como un proceso de comunicación revolucionaria por parte de los esclavos de Coro (1795) donde se originó este efecto social desde la dimensión comunicativa. El modelo a ser contrariado, es la historia oficial que descalifica el tomar decisiones de los esclavos para hacer u organizar acciones revolucionarias, la causa es esa invisibilización de la historia que la convierte en una ciencia discriminatoria, la intención es dejar sentado que los procesos revolucionarios emprendidos en los Siglo XVIII y XIX en América Latina y el Caribe, surgieron como hecho de saberes de las clases mantuanas. Aspectos que se siguen repitiendo en la ciencia histórica, en cada vertiente, diferentes autores han legitimado con ella las actuaciones coloniales, como el caso de Federico Engels quien justificó el futuro tutelaje de los Estados Unidos en la región basado en la violencia en que se mantenían los diferentes países (Saladino, 2010). No sólo la ciencia histórica tergiversa a las realidades culturales de la región, sino las otras ciencias sociales cuando se convierten en la ciencia occidental tratando temas y códigos en la región.

Las religiones de África subsaharianas no se conservaron en un estado puro, pues al contacto, y así es como creemos que hay que entenderlas, con los códigos civilizatorios, tanto amerindios como europeos, marcharon en un proceso de paralelismo religioso y no de sincretismos como impuso la escuela antropológica norteamericana herskoviana o religiones sincréticas como es la moda del momento, sobre todo en Cuba (Tesis G Nro. 2, p. 52).

El modelo integrado que asume las interpretaciones anteriores sobre la religiosidad africana en América, es una ciencia latinoamericana que tiene estrategias para leer la complejidad donde se sitúa la misma. En ciencia no hay una desaparición de la huella africana y expone, un proceso paralelo donde se pueden observar cómo se nutre el sistema de espiritualidad y las imágenes que surgen de la cultura después del éxodo africano sobre todo al Caribe. La ciencia sobre lo latinoamericano y caribeño, trabaja por supuesto con la memoria porque allí, de manera fragmentada, es donde pervive la sabiduría para mantener en la cotidianidad la resistencia al denominado 
Antecedentes y temáticas de la investigación universitaria venezolana sobre Latinoamérica y el Caribe

sincretismo, acción que presentaría una nueva variación religiosa a veces con nuevas imágenes (Waldman, 2006). De la imagen de violencia se pasa al código de resistencia de los más pobres, los mismos conservaron su memoria, para ello hay una transición entre imágenes, de la violencia a la ciencia crítica, planteada desde intelectuales comprometidos con el saber marginado por la historia oficial, se pasa a la existencia de organización y planificación para mantener la memoria de África.

He aquí una muestra de cómo por la vía de la represión se trató de imponer la religión cristiana a esta expresión afrocubana, la cual de una forma muy audaz utilizó el "Cristo" como un requisito aislado para la realización de sus ceremonias.

La sociedad Secreta abakuá tiene su juego de tambores para ejecutar las ceremonias en el fambá y para las procesiones públicas. (Tesis G Nro. 3, p. 82).

El modelo de ciencia que se expone para visualizar los vacíos donde la occidentalización mantuvo a la historia de los pobres en América Latina y el Caribe, se hace presente en la focalización de las maneras de organización que tuvieron los esclavos, los mismo, de modo aparencial, aceptaron la religión cristiana, por cuanto la decisión del Cristo que colocaron en el suelo a los pies del altar, es muestra de organización y planificación de resistencia. Hay una revisión del sujeto histórico en la red del discurso escrito sobre América Latina y el Caribe, dentro de la denominada por esta investigación: Ciencias Integradas. Se busca reacomodar o reintepretarterritorios flotantes de su historia, analogía de la historia episódica de Roig (Vignale, 2008-2009) y a su vez, con esa reinterpretación surge la profundización en el imaginario latinoamericano como táctica autoral. También su énfasis en el discurso sobre América Latina y el espacio cultural caribeño, surge en la lectura semiótica de las memorias locales como táctica de exposición, porque registra el fondo de la historia oficial, de aquellos que no dirigieron las guerras de independencia pero que estaban resistiendo y enseñando cómo se hacía la contra-colonización cultural para llegar a ser repúblicas. El situarse en este nivel del discurso, denominado ciencias integrales, le permite exponer a García, en su libro Caribeñidad (2007), una postura 


\section{Raúl García Palma}

Telos Vol. 20, No. 1 (2018). 159-198

de alternatividad en la historia, aspecto que cierra la interpretación a su obra, que gravita en dos aspectos: a) la búsqueda de perspectiva del conocer no eurocéntrico, que amerita otra lectura semiótica de la historia (Lander, 2000) y b) contiene además el tema sobre la diferencia entre historia y memoria ya expuestos por Marc Bloch y Maurice Halbwachs (Sorgentini, 2003), que surge por la misma línea del anterior aspecto, el de las tensiones de ser parte de un proceso ordenado por una ciencia colonizadora.

Siguiendo con el otro texto, de esta última parte de la interpretación sobre las tesis en algunos libros que están en el período abordado y que han interpretado desde la investigación universitaria de Venezuela, el discurso escrito sobre América Latina y el Caribe, se puede resumir algunos caracterizadores, entre estos están: 1) las prácticas autorales para exponer sus temáticas que se sobreponen en los autores y que terminan por hacer énfasis en algún elemento del discurso (Bolívar, 2007); 2) la tendencia en el interdiscurso(Hall, 2010) de la red escritural sobre América Latina y el Caribe, cuya insistencia es ir contra una ciencia colonizadora, para ello parece partir de la siguiente afirmación: una nueva modalidad de ciencia regional, se establece cuando hay temas de una cultura que convocan a la resistencia de la misma, frente a otra para no desaparecer en los embates de violencia que la alteridad negativa ejerce para su dominio y posterior desaparición, esta mecánica inter e infracultural, la han denominado aculturación, transculturación o hibridación. Esa ciencia de lo regional, que busca, en los discursos que presenta lo latinoamericano y caribeño, genera contenidos en sus prácticas con algunos principios que a lo largo de esta investigación han ido surgiendo; y 3) esos principios se ordenan como estrategias de búsqueda en las relaciones dentro del discurso escrito sobre lo latinoamericano y caribeño, este ordenamiento, a su vez, le genera legitimidad en cuanto a la rigurosidad, cuando se pretende explicar cómo es su práctica dependiendo de la formación discursiva, espacio donde se produce el discurso sobre la región. 
Antecedentes y temáticas de la investigación universitaria venezolana sobre Latinoamérica y el Caribe

En el discurso escrito, al cual se ha dirigido esta investigación, el paso entre ser tema y enunciado lo determina ser código restringido o elaborado (Bernstein, 1974). Hay temas y enunciados que se van saturando en el ejercicio que dibuja a una cultura y comienza a representan la comunicación de un pequeño grupo o incluso, de uno de los países que están contenidos sobre el constructo América Latina y el Caribe, así aparece una investigación sectorizada, que casi siempre es escrita por la antropología y sociología como ciencias para la región. Se tienen los estudios sobre las diversas etnias o sobre la cultura popular, es descriptiva y no pretende establecer comparaciones donde se pudiera analizar o reflexionar diferencias y convergencias entre las culturas latinoamericanas y caribeñas. Este manejo del conocimiento sobre el discurso escrito de códigos restringidos, permite conocer y crea puentes entre lo interno y externo a esa cultura.

Desde la existencia en este discurso escrito, pero como código elaborado, es decir desde la búsqueda de una universalidad de sus sentencias, se ha determinado en esta investigación, que existe otro tipo de código, dentro de los saberes y conocimientos que marcan la existencia de una regionalidad, éste está entre el código restringido (lo universal) y el elaborado (lo micro-local). Su lectura más allá de fronteras inmediatas, se realiza en la relación de las formaciones discursivas. Esta relación significativa, se explica y se ordena a partir de la dimensión de conocimientos y saberes multiregionales, aquí se despliega un alcance medio como sus códigos socioculturales y se convierte en la regionalidad de un conocimiento que permite las convergencias y divergencias de historia y memoria de estas culturas. Se presenta por medio de textos escritos, allí están los monumentos (Hernández, 2010) desde "Nuestra América" de José Martí hasta la Filosofía de la Liberación de Enrique Dussel, RodolfoKusch y Arturo Andrés Roig (Scannone, 2009).

La relación en el discurso escrito sobre América Latina y el Caribe, defiende una frontera que se desplaza, se autocalifica como restringida y elaborada hasta lo que no se puede categorizar desde su memoria e historia como convergencia, ésta cuando 


\section{Raúl García Palma}

Telos Vol. 20, No. 1 (2018). 159-198

es desde lo interno la fortalece. En cambio, las divergencias fortalecen las diferencias entre países, fragmenta y es frenada por las convergencias, que actúan desde todos los códigos socioculturales que hacen posible la existencia de la regionalidad. La identidad, la integración o el colonialismo como preocupación de América Latina y el Caribe la dibujan en las búsquedas ajustadas de la modernidad, en cambio las posturas postmodernas de desintegración, desjerarquización y la subalternidad, la problematiza y la convoca a compararse con regionalidades a nivel mundial, consideradas en exclusión por la postmodernidad.

Este es el caso de la última investigación a interpretar, del Profesor JonhBeverley, quien ha sido investigador del Celarg y profesor de varias universidades del país. Su libro Políticas de la teoría. Ensayos sobre subalternidad y hegemonía (2011), se erige frente a la modernidad y a la postmodernidad por considerar que los estudios subalternos son “... una crítica radical del modo de acumulación capitalista y de su lógica de especialización y homogenización de la temporalidad" (Beverley, 2011, p. 17), por lo tanto, es siempre ideológica y se asume desde un nivel político alto, que además se establece al lado de aquellos que luchan por salir de la razón colonial occidental. Se basa en el concepto del subalterno que, para él, así como para el hindú RanajitGuha, (del grupo de los estudios subalternos del sur asiático), es una categoría de negación y al estar al lado de códigos como la identidad o la colonización, éstos se describirán desde el rechazo del saber hegemónico que lo intenta segregar, excluir e invisibilizar. Las tesis a interpretar en esta investigación, pertenecen al texto señalado con anterioridad, en el mismo se denota el intento de legitimar nuevas discusiones, que se debaten en los últimos años en la red del discurso escrito sobre América Latina y el Caribe, aprovechando las diferencias entre países, pero también señalando nuevas formas de potenciarse la derecha dentro de las regiones culturales que convoca esta investigación. También, se crítica a los Estudios Culturales en su desviación formal para plantear estrategias y lograr transformaciones estructurales en las realidades abordadas. 
Antecedentes y temáticas de la investigación universitaria venezolana sobre Latinoamérica y el Caribe

Entonces, el problema con los estudios culturales desde el punto de vista de los estudios subalternos no es tanto su 'neopopulisno mediático' (la caracterización es de Beatriz Sarlo), sino el hecho de que los estudios culturales podrían perpetuar inconscientemente la ideología estética modernista que supuestamente desplazan, al transferir el programa de desfamiliarización o deshabituación de la percepción desde la esfera de la alta cultura hacia las formas de cultura de masas, concebidas ahora como estéticamente dinámicas y más efectivas, más capaces de producir ostranenie (extrañamiento) (Tesis B Nro. 1, p. 39).

Los Estudios Culturales se convertirían en más de lo mismo, es decir una crítica insuficiente y entrampada sobre un contexto, donde se focalizan puntos de interés nuevos, por ser allí donde se está produciendo la "verdadera estética". Pero en la construcción teórica en que se convierten los Estudios de Subalternidad, se preparan para exponer que la hegemonía política no la deben tener aquellos con sensibilidad, para lograr el extrañamiento del arte, éste no es más que la creación de mundos autónomos y autorreferenciales (Molano, 2012). Se señala de esta manera, que los estudios Cuturales, al hacer esta transferencia de lo estético, también permiten que la mercantilización del arte continúe y no se establezca, en el mismo, sus posibilidades de crear compromiso político en quien lo disfruta.

El salto entre Ciencias Positivistas con Teorías Regionales a las Ciencias Integradas, se da a nivel epistemológico, al no aceptar estas últimas la hegemonía de conceptos como la razón y ciencia, ampliando su criticidad y vigilancia sobre la modernidad con nociones como "epistemología otra" o "Pensamiento Fronterizo". Los autores también se desplazan aprovechando elementos de reflexión y análisis, que siempre han significado al interdiscurso y éste puede ser un principio rector en la red del discurso escrito sobre América Latina y el Caribe, en este interdiscurso, en sus modalidades negativas como son: la colonialidad del poder, el capitalismo y el eurocentrismo, las tres apuntan a los códigos restringidos (Bernstein, 1974), que son aquellos con sentido universal y que disminuyen o debilitan la dimensión de conocimientos y saberes multiregionales. 


\section{Raúl García Palma}

Telos Vol. 20, No. 1 (2018). 159-198

Por otra parte, un autor como Quijano (2000), que con las teorías de la dependencia complementó la colonialidad del poder, surge como referencia de los que hacen estudios culturales, esta última criticada por Beverly por su falta de elementos discursivos en cuanto a una transformación estructural.

Desde una posición de élite, se decreta que las únicas alternativas desde las cuales la oposición social al sistema dominante puede ser imaginada y construida son las más marginadas, las más explotadas, las más abyectas. Se podría argumentar que esto representa una extensión del principio de Lenín de que la revolución siempre debe buscar los estratos de la población más oprimidos. Pero en la actual coyuntura, cuando el neoliberalismo se ha convertido en la ideología dominante, aun en lugares donde gobiernos de izquierda tienen el poder formal, la consecuencia efectiva de tal posición podría ser algo más parecido a lo que se llama 'multiculturalismo liberal', es decir, al reconocimiento y respeto de los 'otros' y de sus 'diferencias' pero sin la posibilidad de una transformación estructural (Tesis B Nro. 2, p. 44).

Los Estudios de Subalternidad tienen un Grado 1, en la red de Formaciones Discursivasdel discurso escrito sobre Latinoamérica y el Caribe, donde se presentan como una disciplina politizada al igual que los Estudios Cultuales, que están en el límite entre la regionalidad denominada América Latina y el Caribe con otras situaciones políticas similares en el mundo. Así al exponer la palabra revolución, ésta: a) debe venir con la marca de esa exclusión, desde una conexión con los excluidos no importando dónde estén y b) demostrar que se está realizando desde un hecho revolucionario sobre el mundo. La subalternidad “... siempre debe buscar los estratos de la población más oprimidos" para garantizar que el desmonte sea la transformación estructural de la realidad, o en todo caso, criticar los desbalances teóricos que no permiten la voz de los oprimidos desde todos los ámbitos.

Como conclusión a este punto, donde se reflexionó para caracterizar textos que reflejan la investigación universitaria venezolana,en cuanto a su temática y antecedentes sobre Latinoamérica y el Caribe verificando el por qué permiten presentar y conforman la memoria de esa región (ver Figura Nro. 1), se puede señalar que hay una táctica autoral utilizada por los profesores seleccionados, al retomar en 
Antecedentes y temáticas de la investigación universitaria venezolana sobre Latinoamérica y el Caribe

sus textos códigos socio culturales con historia y considerar la mediación de la memoria para revisar significaciones como emancipación y colonización. La forma discursiva donde se revisita al código integración, es aquella denominada ciencias positivistas, pero formulada desde un sujeto más cercano al trascendental alternativo.

\section{Figura Nro. 1}

Caracterización de textos de investigación universitaria venezolana en cuanto a su temática y antecedentes sobre Latinoamérica y el Caribe verificando el por qué permiten presentar y conforman la memoria de esa región.
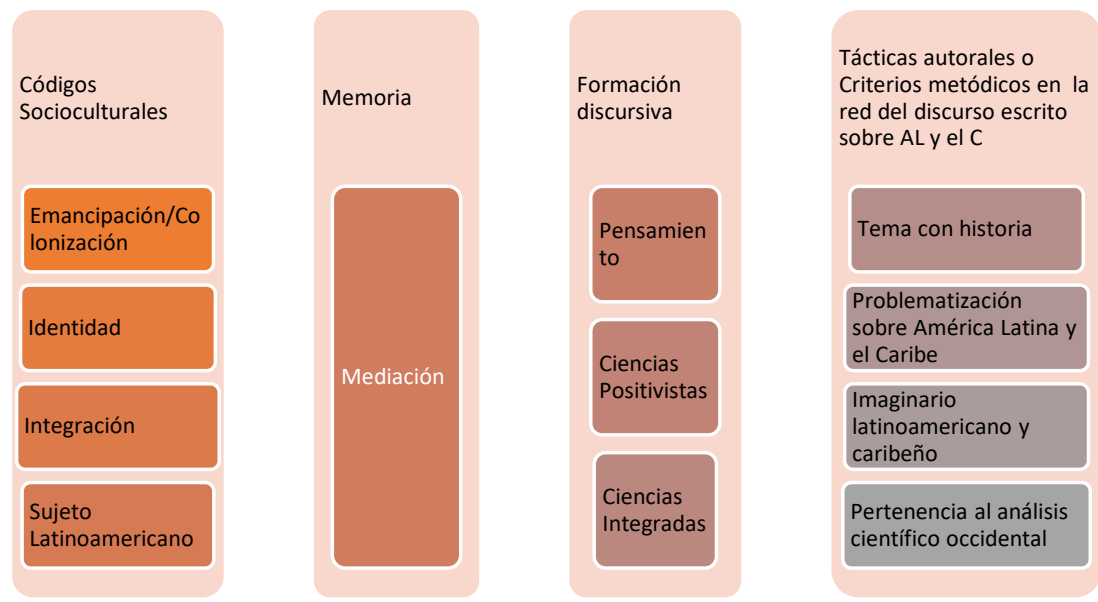

Fuente: Elaboración propia.

En las dos últimas versiones dentro de la red del discurso escrito sobre América Latina y el Caribe, como son las ciencias integradas, donde se encuentran los Estudios Culturales y los de Estudios de Subalternidad, el elemento político se fusiona con el poder de representar en las formaciones discursivas, desde alguna vocería que construye teoría sobre esta realidad. No sólo es representarlo y responder al ¿qué somos? Ahora el qué somos ya fue respondido desde la asimetría de la relación donde se encuentra la región en un sistema-mundo, la pregunta es ¿cómo confrontar-nos en esa asimetría? Para dar respuesta, surge la resignificación del código sociocultural 


\section{Raúl García Palma}

Telos Vol. 20, No. 1 (2018). 159-198

integración sin adjetivos, por el de integración multinacional autónoma (Suárez, 2005), que no es entendida incluso por colectivos de la misma región.

La negación de la posibilidad de solidaridad transnacional es sobre todo una afirmación de la incapacidad del gringo o del nolatinoamericano para entender y 'representar' Latinoamérica. Esto es comprensible en un escenario en que tanto el pasado como el futuro de América Latina involucran una confrontación a todo nivel con el poderío de los Estados Unidos. Pero también hay una negación de la posibilidad de solidaridad entre grupos de diferente formación étnica, cultural, social y lingüística dentro de los confines de cualquier Estadonación latinoamericano o de Latinoamérica como región (Tesis B Nro. 3, p. 132).

La confrontación en un escenario asimétrico, coloca a la región y a los interpretantes que buscan su representación, en lo que puede exponerse como práctica de creación con necesidad de encuentros cognitivos de solidaridad. Solidaridad transnacional que no es minimizar lo propio de las comunidades que marcan diferentes identidades, por la integración a la globalización de las mismas (DíazPolanco, 2016). Reconocer los desplazamientos en la red del discurso escrito sobre América Latina y el Caribe de sus códigos socioculturales, la llegada a ser enunciados y el registrarse como parte de esta red de formaciones discursivas, podrían dar respuesta a la anterior necesidad, aspecto que cierra la interpretación de los textos escritos de los investigadores universitarios sobre el tema.

\section{Conclusiones}

En las formaciones discursivas del discurso escrito sobre América Latina y el Caribe, los tipos de escritura que determinan su identidad cultural han sido ordenadas a través de temáticas y códigos socioculturales, alrededor de búsquedasque conforman la memoria de esta región. Allí también, se sintoniza el sujeto trascendental alternativo con códigos socioculturales autoreflexivos, bajo el signo de la colonialidad. Éste, como investigador, aborda al sujeto latinoamericano y caribeño, que pervive en una relación de naciones con historias parecidas que las convierte también en culturas, con necesidad de colocar en diálogo "el otro sabe que existes, 
Antecedentes y temáticas de la investigación universitaria venezolana sobre Latinoamérica y el Caribe

porque tienes prácticas de creación", afirmación que se sitúa como principio para lograr discursos integrados, pero con solapas evidentes.

Concebir el respeto del otro, sobre la manera de armar conocimiento, modelaje que permita leer las asimetrías, se puede generar con la exploración y la caracterización de los desplazamientos en la red del discurso escrito sobre América Latina y el Caribe, resguardados de la desjerarquización cultural reforzada con la modernidad, en la afirmación distinguida como principio de integración.

\section{Referencias Bibliográficas}

Acosta, Yamandú (Jul, 2009) Historia de las ideas e identidad. Revista ESTUDIOS DE FILOSOFÍA PRÁCTICA E HISTORIA DE LAS IDEAS. Nro. 1. Vol. 11. Argentina (Pp.33-43).

Acosta, Vladimir (2010) Independencia y emancipación. Élites y pueblo en los procesos independentistas hispanoamericanos. Fundación Celarg: Venezuela. Extraído

dehttp://www.scielo.cl/scielo.php?script=sci_arttext\&pid=S071822012010000100005\&lng=es\&nrm=isoConsulta: 27/05/2013.

Alonso, María Nieves; Blum, Andrea; Cerda, Kristov; Cid, Juan; Oelker, Dieter; Sánchez, Marcelo; Triviños, Gilberto y Villavicencio, Manuel (2005) "Donde nadie ha estado todavía": Utopía, retórica, esperanza. Extraído de http://www.scielo.cl/scielo.php?pid=S071804622005000100004\&script=sci_arttext Consulta: 28/11/2011.

Ayala, Mario y Mora Queipo, Ernesto (2008) Reconstrucciones identitarias en el proceso bolivariano: los afrovenezolanos (1998-2008). Extraído de http://bibliotecavirtual.clacso.org.ar/Argentina/ceaunc/20100322033648/ayala.pdfConsulta: 23/02/2015.

Beverley, John(2011) Políticas de la Teoría. Ensayos sobre subalternidad y hegemonía. Colección Nuestra América. Fundación Celarg: Venezuela.

BigottSuzzarini, Belkis V (Ene, 2007) Consumo cultural y educación.Extraído dehttp://www.scielo.org.ve/scielo.php?script=sci_arttext\&pid=S1010-

29142007000100005 Consulta: 03/12/2015.

Bolívar, Adriana (2007) (Compiladora) Análisis Crítico del Discurso ¿Por qué y para qué? Colección Minerva. Nro. 55. Universidad Central de Venezuela: Venezuela.

Castro-Gómez, Santiago y Mendieta, Eduardo (1998) Teorías sin disciplina (latinoamericanismo, poscolonialidad y globalización en debate). Extraído de 
Telos Vol. 20, No. 1 (2018). 159-198

http://people.duke.edu/ wmignolo/InteractiveCV/Publications/Teoriassindiscipl ina.pdf Consulta: 09/11/2013.

Charbel, Joao Queiroz (2007) La emergencia de significado en sistemas semióticos.

Extraído de

http://www.scielo.org.ve/scielo.php?script=sci_arttext\&pid=S0798-

11712007000200002 Consulta: 22/04/2016.

Cordero, Marcela (2000) El componente 'tesis' en los textos argumentativos escolares.

Extraído de http://www.scielo.cl/scielo.php?script=sci_arttext\&pid=S071809342000004800007\&lng=es\&nrm=iso Consulta: 22/05/2013.

Dávila Mendoza, Dora (2010) Agentes de su libertad. Esclavos, sujetos y discursos en un Caribe que cambia (1790-1800). Fundación Celarg: Venezuela.

Díaz-Polanco, Héctor (2016) El jardín de las identidades. La comunidad y el poder. Editorial El perro y la rana: Venezuela.

Espinosa Moreno, Elizabeth Gabriela y Arellano Hernández, Antonio (2010) Hacia una epistemología de la comunicología: la teoría de la comunicación en Serres y en Martín-Barbero Extraído de http://www.scielo.org.mx/scielo.php?script=sci_arttext\&pid=S140514352010000100012 Consulta: 12/10/2014.

Fernández-Nadal, Estela (1999) A propósito de la Historia de las Ideas Latinoamericanas. Utopía y Praxis Latinoamericana. Nro. 6. Año 4. № 6 . Maracaibo: Universidad del Zulia. (Pp.7-31).

Foucault, Michel (1984) La arqueología del saber. Edición utilizada: Editorial Gallimard: Francia

García, Jesús Chucho (2007) Caribeñidad. Biblioteca Popular para los Consejos comunales. Serie Visión de América. El perro y la rana: Venezuela.

García Palma, Raúl (2013) Interpretación del modelo amerindio como antecedente de las culturas latinoamericanas. Extraído dehttp://www.saber.ula.ve/bitstream/123456789/37341/1/articulo_5.pdf Consulta: 12/09/2013.

Grosfoguel, Ramón (2007) Descolonizando los universalismos occidentales: el pluriversalismotransmodernodecolonial desde Aimé Césaire hasta los zapatistas. El giro decolonial: reflexiones para una diversidad epistémica más allá del capitalismo global / Compiladores Santiago Castro-Gómez y Ramón Grosfoguel. Siglo del Hombre Editores; Universidad Central, Instituto de Estudios Sociales Contemporáneos y Pontificia Universidad Javeriana, Instituto Pensar. Colombia.

Guanipa Pérez, María (2011) Opciones epistemológicas y la relación dialógica en la investigación. Revista TELOS. Vol.13. Nro. 1. Venezuela. (Pp. 89-102).

Hall, Beatriz (2010. La construcción de sentido: el caso de los enunciados metafóricos y el discurso académico. Disponible: http://www.scielo.org.mx/scielo.php?script=sci_arttext\&pid=S166512002010000100006\&lng=es\&nrm=iso Consulta: 05/12/2011. 
Antecedentes y temáticas de la investigación universitaria venezolana sobre Latinoamérica y el Caribe

Hernández Castellanos, Donovan Adrián (2010)Arqueología del saber y el orden del discurso: un comentario sobre las formaciones discursivas.Extraído de http://www.scielo.org.mx/scielo.php?script=sci_arttext\&pid=S1870-

879X2010000100003\&lng=es\&nrm=iso Consulta: 01/08/2012.

Hernández de R, Nereyda C y Sánchez, Manuela V (2008a) Divergencias y convergencias en la teoría fundamentada (Método comparativo continuo).Extraído de http://servicio.bc.uc.edu.ve/educacion/revista/n32/326.pdf Consulta: 06/01/2013.

Hernández O, Biviana (2008b) América Latina en sus narrativas: ensayo, novela histórica e historiografía social. Revista Austral de Ciencias Sociales. Nro.15. Chile: Facultad de Filosofía y Humanidades, Instituto de Ciencias Sociales, Universidad Austral de Chile. (Pp. 45-62).

Ibáñez, Romualdo (2007 Cognición y comprensión: Una aproximación histórica y crítica al trabajo investigativo de RolfZwaan.Revista SIGNOS. Vol.40. No.

63. Chile: Pontificia Universidad Católica de Valparaíso. (Pp. 81-100).

Mazorco Irureta, Graciela (2010) La descolonización en tiempos del Pachakutik.Extraído

http://www.scielo.cl/scielo.php?script=sci_arttext\&pid=S0718-

65682010000300010\&lng=es\&nrm=isoConsulta: 22/08/2013.

Mellado, Luciana Andrea (2008) Aproximaciones a la idea de nación: convergencias y ambivalencias de una comunidad imaginada.RevistaALPHA. No. 26. Chile: Universidad de Los Lagos (Pp. 29-45).

Molano, Mario Alejandro (2012) Desafíos para una teoría del arte: experiencia estética, institución y función social. Extraído de http://www.scielo.cl/scielo.php?script=sci_arttext\&pid=S071871812012000100005\&lng=es\&nrm=iso Consulta: 02/06/2013.

Morán Beltrán, Lino E (Ene, 2006) De la teoría de la complejidad a la filosofía intercultural: hacia un nuevo saber. Extraído dehttp://www.scielo.org.ve/scielo.php?script=sci_arttext\&pid=S0798-

11712006000100004\&lng=es\&nrm=iso. Consulta: 19/11/2011.

Noel Lapoujade, María (2004)Los imaginarios en la construcción de la identidad latinoamericana.

dehttp://www.scielo.org.ve/scielo.php?script=sci_arttext\&pid=S0798-

11712004000300004\&lng=es\&nrm Consulta: 26/11/2011.

Olivares, María Alejandra (2012) Brathwaite, Kamau: La unidad submarina: ensayos caribeños. Selección, estudio preliminar y entrevista de Florencia Bonfiglio. Buenos Aires, Katatay, 2010. Extraído de http://www.scielo.org.ar/scielo.php?script=sci_arttext\&pid=S185146692012000200007\&lng=es\&nrm=iso Consulta: 07/11/2013.

Ortega, Francisco A (2011) Tomen lo bueno, dejen lo malo: Simón Rodríguez y la educación

popular.Extraído

de 
$29 / 08 / 2013$.

Paz, Octavio (1998) El laberinto de la soledad. 2da Impresión. Extraído de http://www.hacer.org/pdf/Paz00.pdf (Consulta: 25/05/2013).

Pineda Franco, Adela (2009) Entre la ciudad real y la ciudad letrada: Rubén Darío y el modernismo en la visión culturalista de Ángel Rama. Extraído de http://www.scielo.org.ar/scielo.php?script=sci_arttext\&pid=S1852-

96152009000100009\&lng=es\&nrm=iso Consulta: 11/11/2013.

Porto-Goncalves, Carlos Walter (2009) De Saberes y de Territorios: diversidad y emancipación a partir de la experiencia latino-americana. Extraído de http://www.scielo.cl/scielo.php?script=sci_arttext\&pid=S071865682009000100008\&lng=es\&nrm=iso Consulta: 26/05/2013.

Quijano, Aníbal (2000) Colonialidad del poder, eurocentrismo y América Latina. Lander, E. (comp.) La colonialidad del saber: eurocentrismo y ciencias sociales. Perspectivas latinoamericanas. CLACSO: Argentina.

Quintero, María del Pilar (2008) Sueños y palabras de América Latina. Archivo Arquidiocesano de Mérida. Serie Estudios. 5. Arquidiócesis de Mérida/ Archivo Arquidiocesano de Mérida/AMM: Venezuela.

Quintero-Montilla, María del Pilar (2009). Una contribución para el diálogo intercultural: algunas interpretaciones en torno a la cosmovisión amerindia. Extraído de http://www.scielo.org.ve/scielo.php?script=sci_arttext\&pid=S131552162009000200009\&lng=es\&nrm=iso Consulta: 12/07/2011.

Quintero-Montilla, María del Pilar (Ene-Dic, 2011) Ética intercultural y comunidades de diálogo y argumentación intercultural para la población criolla venezolana y latinoamericana. Consciencia y Diálogo. Nro.2. Año 2. Mérida: ULA. (Pp. 2948).

Rama, Ángel (1985) La crítica de la cultura en América Latina. Nro. 119. Editorial Ayacucho: Venezuela.

Ray, Marilyn A (2003) La riqueza de la fenomenología: preocupaciones filosóficas, teóricas y metodológicas. Morse, J. M, edit: Asuntos críticos en los métodos de investigación cualitativa. Facultad de Enfermería de la Universidad de Antioquia: Colombia.

Roig, Jorge (2008) El pensamiento latinoamericano y su aventura. Ediciones El Andariego: Argentina.

Saladino García, Alberto (2010) El Latinoamericanismo como Pensamiento Descolonizador.Extraído de

http://www.scielo.cl/scielo.php?script=sci_arttext\&pid=S0718-

23762010000200011\&lng=es\&nrm=iso Consulta: 19/11/2011.

Scannone, Juan Carlos (2009) La filosofía de la liberación: historia, características, vigencia actual. Extraído de 
Antecedentes y temáticas de la investigación universitaria venezolana sobre Latinoamérica y el Caribe

https://repositorio.uc.cl/bitstream/handle/11534/5828/000525715.pdf?sequen ce $=1 \&$ isAllowed $=y$ Consulta: $12 / 10 / 2015$.

Sorgentini, Hernán (2003) Reflexión sobre la memoria y autorreflexión de la historia.

Extraído de http://www.scielo.br/scielo.php?script=sci arttext\&pid=S010201882003000100005Consulta: 19 Consulta: 19/11/2011./11/2011.

Suárez Salazar, Luís (2005) La integración multinacional latinoamericana y caribeña: un enfoque desde la prospectiva crítica y participativa. SOCIOLOGÍAS. Nro. 14. Año 7. (Porto Alegre) Brasil: Programa de Postgrado en Sociología de la UFRGS. (Pp. 62-109).

Vergara, Jorge Iván; Vergara Estévez, Jorge y Gundermann, Hans (2010) Elementos para una teoría crítica de las identidades culturales en América Latina. Extraído de http://www.scielo.org.ve/scielo.php?script=sci_arttext\&pid=S131552162010000400005\&lng=es\&nrm=iso Consulta: 25/05/2013.

Vignale, Silvana (2008-2009) La cuestión del método para un "pensamiento latinoamericano" en Arturo Roig. Extraído de: http://www.scielo.org.ar/scielo.php?script=sci_arttext\&pid=S185331752008000100003 Consulta: 12/04/2013.

Waldman M., Gilda (2006) La "cultura de la memoria": problemas y reflexiones. Política y Cultura. Nro.26. México. (Pp. 11-34).

Yehia, Elena (2007) Descolonización del conocimiento y la práctica: un encuentro dialógico entre el programa de investigación sobre modernidad /colonialidad / decolonialidad latinoamericanas y la teoría actor-red. Tabula Rasa. Nro.6. Colombia: (Pp. 85-114).

Zea, Leopoldo (1969) La filosofía americana como filosofía sin más. Siglo XXI Editores: México. 